\title{
Modifications of oxidized Zircaloy-4 surface in contact with radiolysed wet air
}

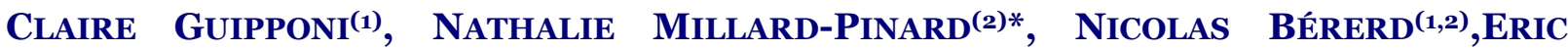 \\ SERris(3), Michèle PiJOlat(3), Véronique Peres(3), Virginie WASSElin-Trupin(4) \\ (1) Université Claude Bernard Lyon 1, Institut de Physique Nucléaire de Lyon, CNRS \\ UMR 5822, 4 rue Enrico Fermi, 69622 Villeurbanne Cedex, France \\ (2) Université Claude Bernard Lyon 1, UCBL-IUT Lyon 1, département chimie, 43 \\ Boulevard du 11 novembre 1918, F-69622 Villeurbanne Cedex, France \\ (3) Ecole Nationale Supérieure des Mines de Saint Etienne, Centre SPIN ; Département \\ PRESSIC ; LPMG-UMR CNRS 5148, 158 Cours Fauriel - 42023 Saint-Étienne Cedex 2, \\ France \\ (4) Institut de Radioprotection et de Sûreté Nucléaire, BP 17, 92262 Fontenay aux Roses, \\ France
}

\begin{abstract}
In the framework of radioactive waste geological disposal, the long term evolution of the nuclear wastes packages and the release of the radionuclides from the wastes have to be studied. Regarding compacted wastes (cladding tubes) coming from reprocessing of spent fuel, the Zircaloy-4 (zirconium alloy) cladding tubes have been activated and oxidized in reactors. In the disposal, the radioactive waste is exposed to humid air in a first phase and to water after the resaturation phase. In order to better assess the degradation process of these nuclear waste package, the influence of wet air proton radiolysis on the behavior of surface oxidized Zircaloy- 4 has been investigated. Radiolysis experiments were performed using an irradiation cell which is associated to an extracted beam. Samples are exposed to wet air, under and without radiolysis, during 12 and $24 \mathrm{~h}$. The water partial pressure has been fixed at 6 and 50 mbar in order to have, respectively, localized adsorbed water molecules and a thin film of adsorbed water. Before and after each treatment, sample surfaces were characterized by X-ray Photoelectron Spectroscopy (XPS) in order to identify the elements at the topmost surface of the solid.

The wet air radiolysis causes changes at the surface of oxidized Zircaloy-4 and influences the corrosion phenomenon. Indeed, an enrichment of tin and the presence of nitrogen species were observed. It could be due to the formation of tritin(II) tetrahydroxide dinitrate and a $\mathrm{Zr}^{4+}$ tetramer on the topmost oxide surface.
\end{abstract}

Keywords:

Zircaloy-4; Radiolysis; Wet air; XPS

\section{Introduction}

At the end of the light water reactor operations, Zircaloy (zirconium alloy) cladding tubes have been activated and oxidized. In France, the reprocessing of nuclear fuel assemblies gives rise to the formation of compacted wastes [1]. Indeed, the metal pieces are sheared, compacted in a wafer form, placed into a steel container and then into a concrete over-pack. Surfaces of the Zircaloy 4 are contaminated by activation products, fission products and actinides. In a

\footnotetext{
* Corresponding author : millard@inpl.in2p3.fr
} 
possible repository in deep geological layer, the release of radionuclides contained in the compacted wastes would take place after the alteration of Zircaloy in contact with water resaturation site [2]. This water, at first in vapor phase, then in liquid form, is irradiated. The irradiation induces a phenomenon called water radiolysis which may accelerate the corrosion of oxidized Zircaloy-4.

In this context, this study is performed to highlight the effects of wet air radiolysis on the oxidized Zircaloy-4 surface. In order to simplify the conceptual model, we synthesized a $6 \mu \mathrm{m}$ porous oxide layer to establish a model of the oxidized Zircaloy-4 layer formed in reactor. The porous oxide preparation was controlled by thermogravimetry [3]. We have chosen to simulate alpha radiolysis by proton irradiations. An experiment cell has been performed.

In this paper, we will study the corrosion of an oxidized Zircaloy-4 layer in contact with irradiated wet air which is irradiated by $1.5 \mathrm{MeV}$ protons to induce radiolysis. In order to better identify the radiolysis effects on sample surfaces, experiments without irradiation were performed: samples are only in contact with wet air (blank). By comparing the experiments with and without radiolysis, the effect of radiolysed wet air on the oxide topmost surface is highlighted.

\section{Materials and methods}

\section{II.1. Samples}

Samples are $420 \mathrm{~m}$ thick Zircaloy-4 foils cut to $10 \mathrm{~mm} 310 \mathrm{~mm}$. The zirconium alloy is composed of tin (1.4 wt\%), iron and chromium (less than 0.2 wt\% each). Samples are oxidized during $52 \mathrm{~h}$ in a mixed $\mathrm{O}_{2} / \mathrm{He}$ atmosphere in order to form an oxide layer thickness equal to $6 \mu \mathrm{m}$ [3]. In these conditions, the kinetic transition is reached and the formed oxide contains several cracks which are parallels and perpendiculars to the metal oxide interface [4]. Those cracks are likely to accelerate transport of chemical species deep in the material and thus to accelerate chemical reactions.

In the following, it will be referred as the initial state.

\section{II.2. Proton irradiations}

Irradiation experiments are performed using a $1.5 \mathrm{MeV}$ energy proton beam using the Van de Graaff accelerator of the "Institut de Physique Nucléaire de Lyon" [5]. Figure 1 illustrates the experimental set up. Protons are extracted from a $10 \mu \mathrm{m}$ Havar window foil to the atmospheric pressure. They entered into air at $673 \mathrm{keV}$ kinetic energy and stopped at $2 \mathrm{~mm}$ from the oxidized surface. In these conditions, only the gas is irradiated. The irradiation cell characteristics and humid air formation have been described in detail in a previous paper [3]. Samples are putted in contact with wet air without irradiation (referred as blank) and with radiolysed atmosphere (referred as radiolysed) during 12 and $24 \mathrm{~h}$. For $12 \mathrm{~h}$ experiments, the irradiation fluence is equal to $1.4 \times 10^{16}$ protons $\mathrm{cm}^{-2}$. Two water partial pressures are used, 6 and 50 mbar, in order to have water under two states at the topmost surface of the oxidized solid: at 6 mbar, the water is localized adsorbed, whereas, at 50 mbar, the water absorbed forms a thin water layer [6].

\section{II.3. Oxide characterization}

XPS analysis are carried out at the "Ecole Nationale Supérieure des Mines de Saint Etienne" using a spectrometer with an unchromated $\mathrm{Al} \mathrm{Ka}(1486.6 \mathrm{eV})$ radiation. Figure 2 displays the XPS spectrum of a typical initial sample.

Binding energy positions are corrected using the $\mathrm{C}$ 1s carbon contamination peak $(284.8 \mathrm{eV}$ [7]). Oxygen, zirconium, carbon and tin are presents on the topmost surface of the initial sample. The peak position allows the determination of the chemical state of each element.

Iron and chromium signals are not detected because their concentrations are below the XPS detection limit (1 wt\%). In this study, in order to compare the evolution of each sample, we have realized a semi-quantitative analysis and we have calculated the atomic ratios compared to zirconium $(\mathrm{O} / \mathrm{Zr}, \mathrm{Sn} / \mathrm{Zr})$. 


\section{Results}

\section{III.1. Study of oxygen species formation}

The initial sample $1 \mathrm{~S} \mathrm{O}$ peak shows a major contribution close to $530 \mathrm{eV}$ attributed to the oxygen in the zirconia [8] and [9]. By comparison of the signal after each treatment (blank and radiolysis), we note that the $\mathrm{O}$ 1s peak shape changes and the peak maximum is shifted towards higher energy as soon as samples are exposed to wet air (Figure 3(a) and (b)). At 6 and 50 mbar, topmost surface modifications occur characterized by several oxygen chemical states. To identify new oxygen species at the sample surface, we use processing CASAXPS software to separate each component. We have proposed and attributed the presence of three components in the overall peak (Figure 4). The first one, at $529.8 \mathrm{eV}$, corresponds to $\mathrm{O}_{2}$ - in the zirconia signal [8] and [9]. The second component close to $531.7 \mathrm{eV}$ is attributed to the $\mathrm{OH}$ - from the adsorbed water [10] and [11]. At $532.8 \mathrm{eV}$, the third component is assigned to $\mathrm{H}_{2} \mathrm{O}$ species which correspond to physisorbed water [12] and [13].

The signal intensity $I_{i}$, is defined by the follow relationship:

$$
I_{i}=K \cdot N_{i} \cdot\left(\frac{d \sigma}{d \Omega}\right)_{i} \cdot \lambda_{i}
$$

where $K, N_{i},\left(\frac{d \sigma}{d \Omega}\right)_{i}$ and $\lambda_{i}$ are, respectively, the device constant, the number of atoms $i$, the photoionisation cross-section [14] and the mean free path of photoelectron.

Using this relationship for two elements $i$ and $j$, we determine the atomic ratio by the Equation (2).

$$
\frac{N_{i}}{N_{j}}=\frac{I_{i}}{I_{j}} \cdot \frac{\left(\frac{d \sigma}{d \Omega}\right)_{j}}{\left(\frac{d \sigma}{d \Omega}\right)_{i}}
$$

We have followed the atomic ratio evolution for each oxygen group as a function of irradiation time. Figure 5 represents the evolution of $\mathrm{O}_{2-}$ form (a) and $\mathrm{OH}^{-}$form (b) atomic ratios compared to zirconium. Each experiment is performed twice. The blank experiment results are represented for an irradiation time equal to zero.

Theoretically, the stoichiometry of oxygen in zirconium oxide is equal to $2\left(\mathrm{ZrO}_{2}\right)$. The $\mathrm{O}_{0^{2}} / \mathrm{Zr}$ atomic ratio keeps constant at 6 mbar while at 50 mbar it decreases. For hydroxyl atomic ratio, despite a lack of reproducibility, we observe a maximum after the irradiations of $12 \mathrm{~h}$.

\section{III.2. Tin enrichment and nitrogen presence at the oxide surface}

Figure 6 corresponds to the 3d Sn photoelectron signal at 6 mbar (a) and 50 mbar (b) for initial, blank and radiolysis samples. At $6 \mathrm{mbar}$, no difference is observed whatever the treatment. At 50 mbar, after radiolysis experiments, the signal to noise ratio put in evidence a tin enrichment. The binding energies of $3 \mathrm{~d} \mathrm{Sn}$ and $3 \mathrm{~s} \mathrm{Zr}$ photoelectrons are, respectively, equal to $486.4,495.2 \mathrm{eV}\left(3 \mathrm{~d}_{5 / 2}\right.$ and $\left.3 \mathrm{~d}_{3 / 2}\right)$ and $433.1 \mathrm{eV}$.

By comparing spectra obtained before and after irradiation experiments at 6 and 50 mbar, a peak appears after radiolysis experiment at a binding energy equal to $401.5 \mathrm{eV}$ (Figure 7). This peak was attributed to nitrogen bounded to oxygen like $\mathrm{NO}_{3}$ species [7].

Like oxygen species, we calculated the atomic ratios of nitrogen and tin compared to the zirconium (Figure 8).

Two different behaviors have been observed. At 6 mbar, whatever the element (tin or nitrogen), the atomic ratios increase with the duration of contact with radiolyzed atmosphere. At 50 mbar, in the same way as for hydroxyl, the tin and nitrogen atomic ratios present a maximum for $12 \mathrm{~h}$. This last observation suggests that $\mathrm{OH}, \mathrm{Sn}$ and $\mathrm{NO}_{3}$ species are correlated. Moreover, in a previous work [3], we showed that there was no oxide loss during irradiation. A 
formation of a compound containing tin, hydroxyl and nitrate groups could explain the enrichment of tin and the nitrogen presence at the topmost surface after wet air radiolysis experiment. Cotton and Donaldson [15] and [16] have observed such a compound, the tritin(II) tetrahydroxide dinitrate which formula is $\mathrm{Sn}_{3}(\mathrm{OH})_{4}\left(\mathrm{NO}_{3}\right)_{2}$. In the way to verify this hypothesis, we have calculated $\mathrm{O}_{\text {он }} / \mathrm{Sn}$ and $\mathrm{N} / \mathrm{Sn}$ atomic ratios (Table 1 ).

These results show important variations of ratios as a function of experimental conditions.

At 6 mbar, ratio values vary strongly and, in these conditions, it is not possible to establish a correlation between $\mathrm{O}_{\text {он}} / \mathrm{Sn}$ and N/Sn atomic ratios.

At 50 mbar, the $\mathrm{O}_{\text {он }} / \mathrm{Sn}$ and $\mathrm{N} / \mathrm{Sn}$ atomic ratios are less dispersed than at 6 mbar. Despite this observation, the atomic ratio values are too high to correspond exactly to the $\mathrm{Sn}_{3}(\mathrm{OH})_{4}\left(\mathrm{NO}_{3}\right)_{2}$ compound. The thickness probed by XPS analyses being about $10 \mathrm{~nm}$, the detected signal results to the zirconia/ $\mathrm{Sn}_{3}(\mathrm{OH})_{4}\left(\mathrm{NO}_{3}\right)_{2}$ mixture. Consequently, XPS calculations cannot indicate the stoichiometry of the compound.

In order to put in evidence the water impact in the radiolysed species formation, we performed experiments using dry air. XPS analyses have not revealed a $\mathrm{N}$ signal in the binding energy range $400405 \mathrm{eV}$. We can then conclude that the presence of water is necessary to give rise to the surface modifications.

\section{Discussion}

Without radiolysis, in contact with wet air, water molecules are adsorbed on the zirconia surface. At 6 mbar, the adsorption is localized whereas at 50 mbar, the water molecules form a thin film of water at the oxide surface. It results an increasing of the relative amount of $\mathrm{OH}$ and $\mathrm{H}_{2} \mathrm{O}$ groups at the zirconia surface.

After radiolysis experiments, results show that nitrogen is present only if the radiolysed air contains water. The $\mathrm{N}$ binding energy indicates that nitrogen is surrounded by oxygen atoms [7]. This observation puts in evidence the formation of nitric acid during wet air radiolysis [17], [18] and [19]. The contact between nitric acid and the zirconia surface explains the nitrogen presence at 6 and 50 mbar on the zirconia surface.

At 6 mbar, the presence of nitrogen is the main observation of oxide surface modification. At 50 mbar, the tin enrichment is the major modification. Initially, the oxide contains 1.4 percents of tin. After the radiolysis experiments, the topmost surface tin atomic concentration is equal to $60 \%$. To explain the different behavior of tin as a function of the water partial pressure, the water molecule system on the oxide surface must be considered. At 50 mbar, the adsorbed water forms a thin film. The acidic environment allows the formation of a tin compound such as the tritin(II) tetrahydroxide dinitrate $\mathrm{Sn}_{3}(\mathrm{OH})_{4}\left(\mathrm{NO}_{3}\right)_{2}$. We propose three steps to describe the formation of this compound:

* Reduction of tin(IV) by reaction with hydrogen to form tin(II). Indeed, tin in zirconia is in $\mathrm{SnO} 2$ form [20].

* Reaction between tin(II) and hydroxyl group [21]

$$
\begin{aligned}
& 3 \mathrm{Sn}_{2+}+4 \mathrm{OH}^{-} \rightarrow\left[\mathrm{Sn}_{3}(\mathrm{OH})^{4}\right]^{2+} \\
& \text { Reaction between }\left[\mathrm{Sn}_{3}(\mathrm{OH})^{4}\right]^{2+} \text { and } \mathrm{NO}_{3}^{-}[16] \\
& {\left[\mathrm{Sn}_{3}(\mathrm{OH})_{4}\right]^{2+}+2 \mathrm{NO}_{3}^{-} \rightarrow \mathrm{Sn}_{3}(\mathrm{OH})_{4}\left(\mathrm{NO}_{3}\right)_{2}}
\end{aligned}
$$

At the same time in the tritin(II) tetrahydroxide dinitrate formation, another surface reaction could occur between $\mathrm{Zr}^{4+}$ and $\mathrm{OH}^{-}$ions. Indeed in acidity environment, the $\left[\mathrm{Zr}_{4}(\mathrm{OH})_{8}\left(\mathrm{H}_{2} \mathrm{O}\right)_{16}\right]^{8+}$ complex can be formed [15]. This Zr compound formation could explain the results obtained by XPS analysis. At 50 mbar, a maximum $\mathrm{Sn}_{\text {compound }} / \mathrm{Zr}$ atomic ratio is observed for $12 \mathrm{~h}$ (Figure 8). In agreement with this hypothesis, the $\mathrm{Zr}$ atoms quantity probed by XPS measurements would be more important for $24 \mathrm{~h}$ than for $12 \mathrm{~h}$. The zirconium signal total intensity would contain two contributions: the signal due to the oxide and the signal due to the $\mathrm{Zr}$ compound present in 
the water thin layer. On the other hand, the $O_{O^{2-}} / \mathrm{Zr}$ atomic ratio is inferior to the values determined to the initial or blank samples as it is observed in Figure 5. This result consolidates the complex formation hypothesis.

\section{Conclusions}

This study has shown the influence of radiolysis of wet air in contact with zirconia on the degradation of the oxide layer. The apparition of nitrogen in topmost surface results in the presence of water in radiolysed air. This is due to the formation of nitric acid. When the water molecules are locally adsorbed (6 mbar), no chemical reaction takes place. New species are presents in topmost surface but no interaction occurs. On the contrary, when water is absorbed as a water thin film (50 mbar), the present species react. Two new compounds form: $\mathrm{Sn}_{3}(\mathrm{OH})_{4}\left(\mathrm{NO}_{3}\right)_{2}$ and $\left[\mathrm{Zr}_{4}(\mathrm{OH})_{8}\left(\mathrm{H}_{2} \mathrm{O}\right)_{16}\right]^{8+}$.

In case of cycles of adsorption and put in contact with liquid water, these formed compounds would be evacuated by the surface allowing a new adsorption and surface reactions cycle. It would be then interesting to evaluate the protective properties of this film formed on surface.

\section{Acknowledgements}

The authors thank all the people who contributed to this work and especially P. Passet of the ENSMSE, C. SERRES of the IRSN and C. Peaucelle, A. Perrat-Mabilon, A. Gardon, Y. Champelovier and R. Fillol from the "accelerator group" of the IPNL.

\section{References}

[1] Plan National de Gestion des Matières et des Déchets Radioactifs, 20072009, http://www.developpement-durable.gouv.fr.

[2] Dossier argile, ANDRA rapport, 2005.

[3] V. Wasselin-Trupin, C. Guipponi, N. Millard-Pinard, E. Serris, M. Pijolat, N. Bérerd, C. Corbel, M.F. Barthe, P.C. Leverd; Researches in safety of compacted waste and spent nuclear fuel; in: High-Level Radioactive Waste Management Conference 2008, Las Vegas, NV, September 711, 2008.

[4] M. Tupin, M. Pijolat, F. Valdivieso, M. Soustelle, A. Frichet, P. Barberis; J. Nucl. Mater., 317 (2003), p. 130

[5] C. Pichon, A. Chevarier, J.C. Duclot, A. Gardon, J.C. Marchand, N. Millard-Pinard, C. Peaucelle, M. Pijolat, F. Valdivieso; Nuclear Instruments and Methods in Physics Research Section B, 240 (2005), p. 589

[6] E. Rodier, L'adsorption (Sciences et techniques des poudres, 2007).

[7] NIST, XPS data table: http://srdata.nist.gov/xps/

[8] P. Keller; XPS investigations of electrochemically formed passive layers on $\mathrm{Fe} / \mathrm{Cr}$ alloys in O.5 $\mathrm{M} \mathrm{H}_{2} \mathrm{SO}_{4}$; Corros. Sci., 46 (2004) 1939

[9] D.Q. Peng, X.D. Bai, X.W. Chen, Q.G. Zhou, X.Y. Liu, R.H. Yu, P.Y. Deng; Surf. Coat. Technol., 190 (2005), p. 271

[10] D. Majumbar, D. Chatterjee; J. Appl. Phys., 70 (2) (1991), p. 988

[11] J. Nakamura, M. Kazuta, S. Kawamura, I. Matsuo, T. Uematsu, T. Yamada, K.I. Tanaka; Surf. Sci., 317 (1994), p. 109

[12] R. Alfonsetti, L. Lozzi, M. Passacantando, P. Picozzi, S. Santucci; Appl. Surf. Sci., 70 (1993), p. 222

[13] C.T. Liu, J.K. Wu; Influence of $\mathrm{pH}$ on the passivation behavior of 254SMO stainless steel in 3,5\% NaCl solution; Corros. Sci., 49 (2007), p. 2198

[14] J.H. Scofield; Hartree-slater subshell photoionization cross-sections at 1254 and 1487 eV; J. Electron Spectrosc. Relat. Phenom., 8 (1976), p. 129

[15] F.A. Cotton, G. Wilkinson; Advanced Inorganic Chemistry, (fifth ed.)Wiley/Interscience (1996) 
[16] J. Donaldson et al.; Characterisation of the tin(II) hydroxide cation $\left[\mathrm{Sn}_{3}(\mathrm{OH})_{4}\right] 2+$ and the crystal structure of tritin; Journal of Chemical Society Dalton Transaction, 2273 (1995), p. 13

[17] Y. Kanda, T. Momose, M. Taira ; Rad. Phys. Chem., 8 (1996), p. 49

[18] Y. Kanda, Y. Oki, S. Yokoyama, K. Sato, H. Noguchi, S. Tanaka, T. Iida; Rad. Phys. Chem., 74 (2005), p. 338

[19] L.N. Less, A.J. Swallow; Nucleonics, 22 (9) (1964), p. 58

[20] Handbook of Chemistry and Physics, 87th ed. 20062007, CRC, 2006.

[21] N. Wiberg, Holleman-Wiberg, Inorganic Chemistry, Academic Press, 2001. 
Nuclear Instruments and Methods in Physics Research Section B: Beam Interactions with Materials and Atoms, 2012, 272, 222-226, doi: 10.1016/j.nimb.2011.01.07O

\section{Figures}

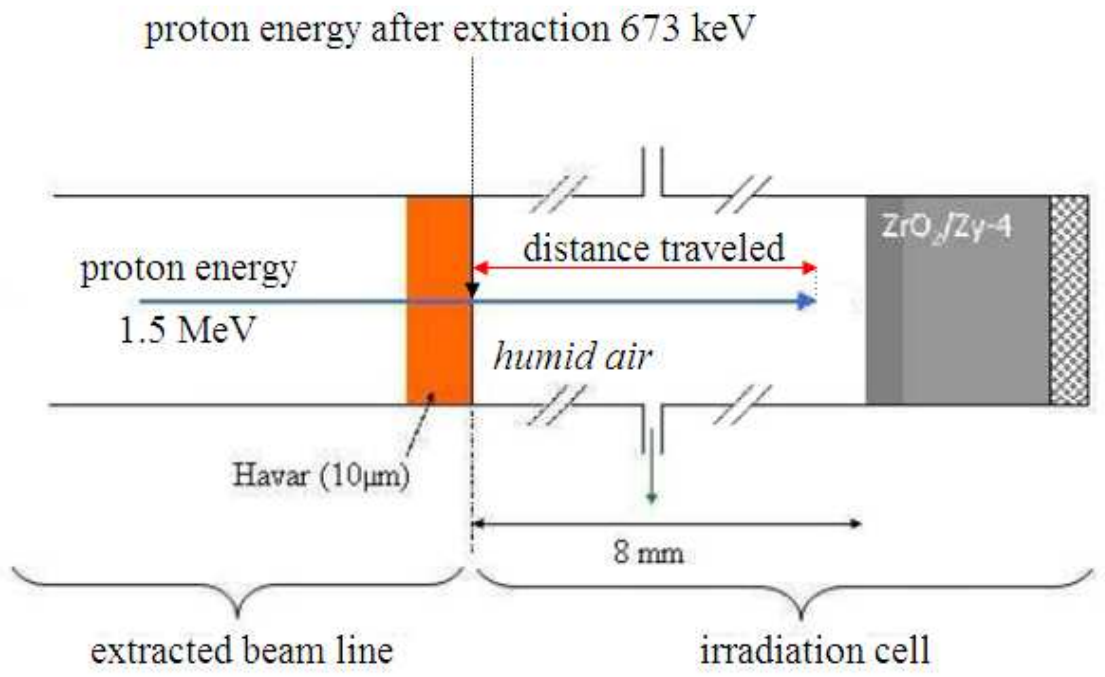

Figure 1: Schematic representation of the irradiation set up under a 1.5 proton beam.

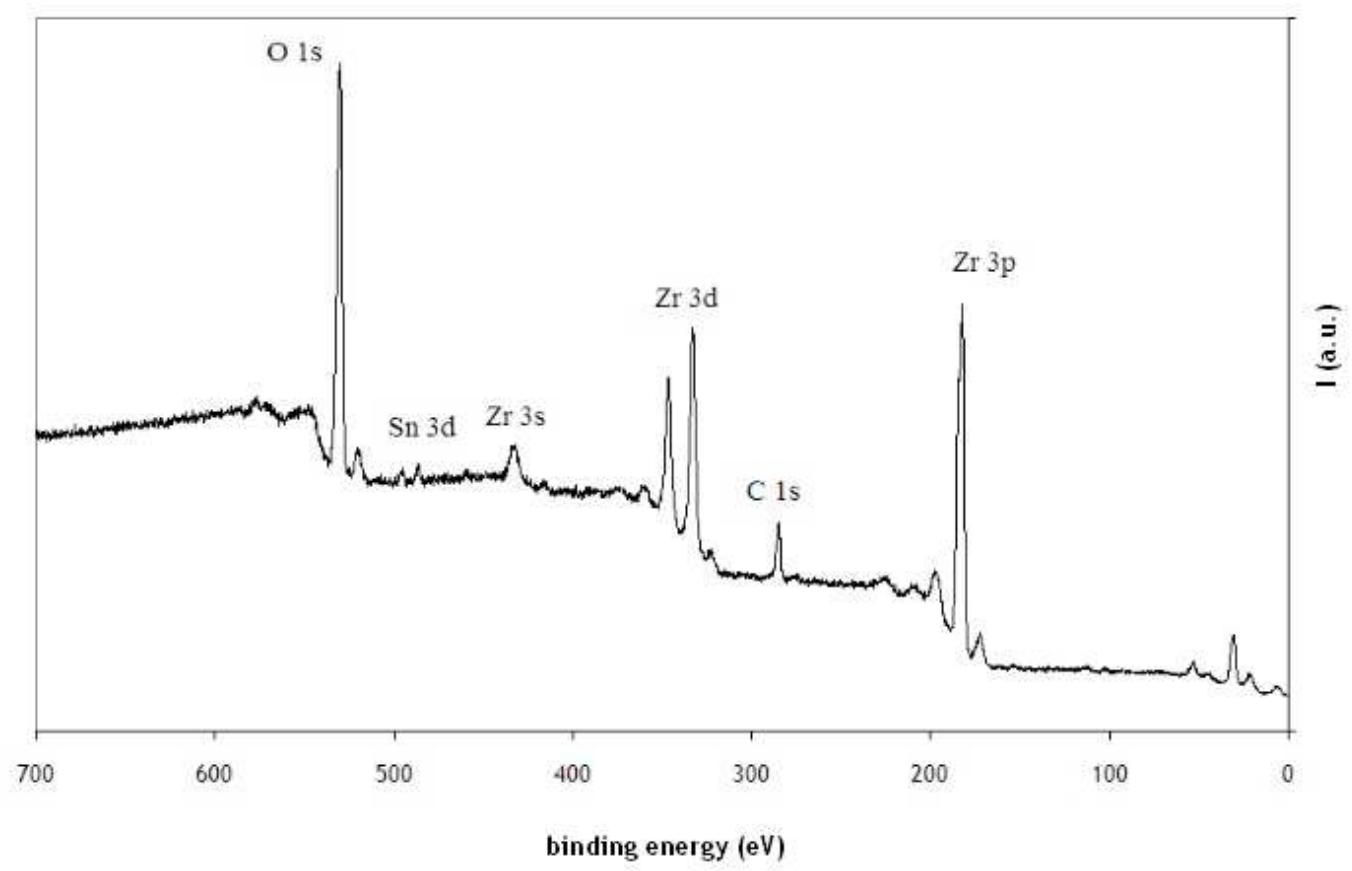

Figure 2: XPS spectrum of a typical initial sample of oxidized Zircaloy-4. 
Nuclear Instruments and Methods in Physics Research Section B: Beam Interactions with Materials and Atoms, 2012, 272, 222-226, doi: 10.1016/j.nimb.2011.01.07O
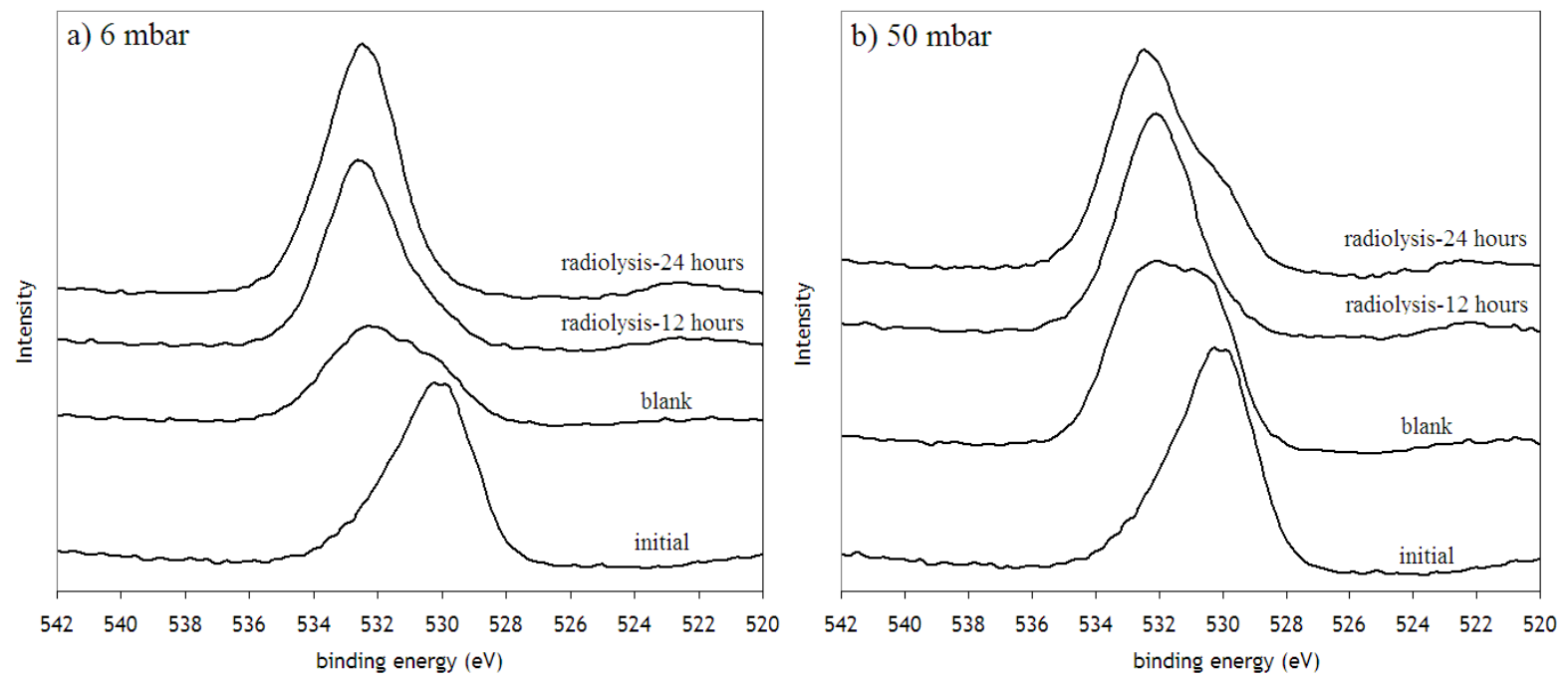

Figure 3: Oxygen signal after experiment at (a) 6 mbar and (b) 50 mbar without and with irradiation, during 12 and $24 \mathrm{~h}$.

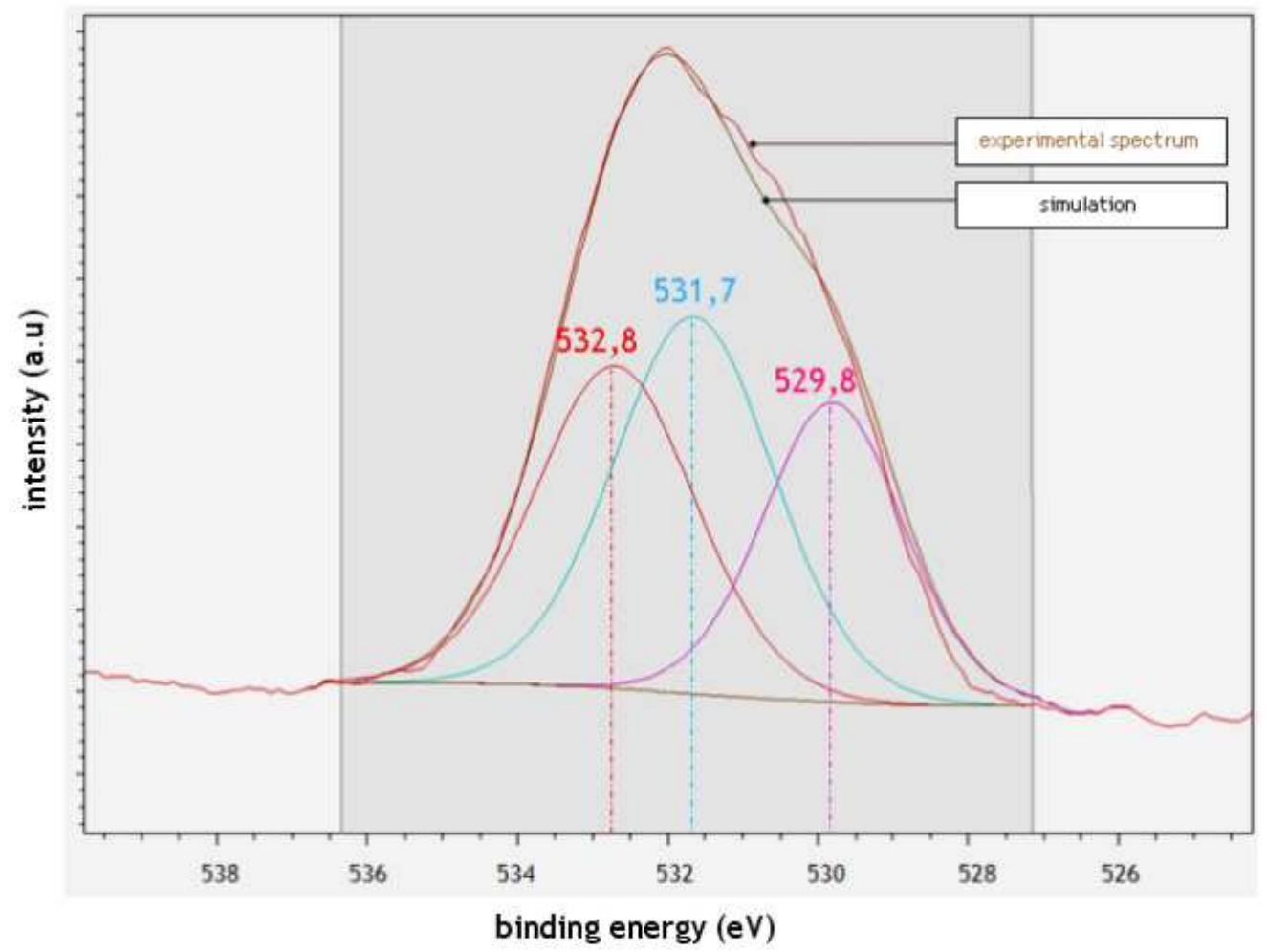

Figure 4: Typical dessomation of oxygen 1s signal. 
Nuclear Instruments and Methods in Physics Research Section B: Beam Interactions with Materials and Atoms, 2012, 272, 222-226, doi: 10.1016/j.nimb.2011.01.07O
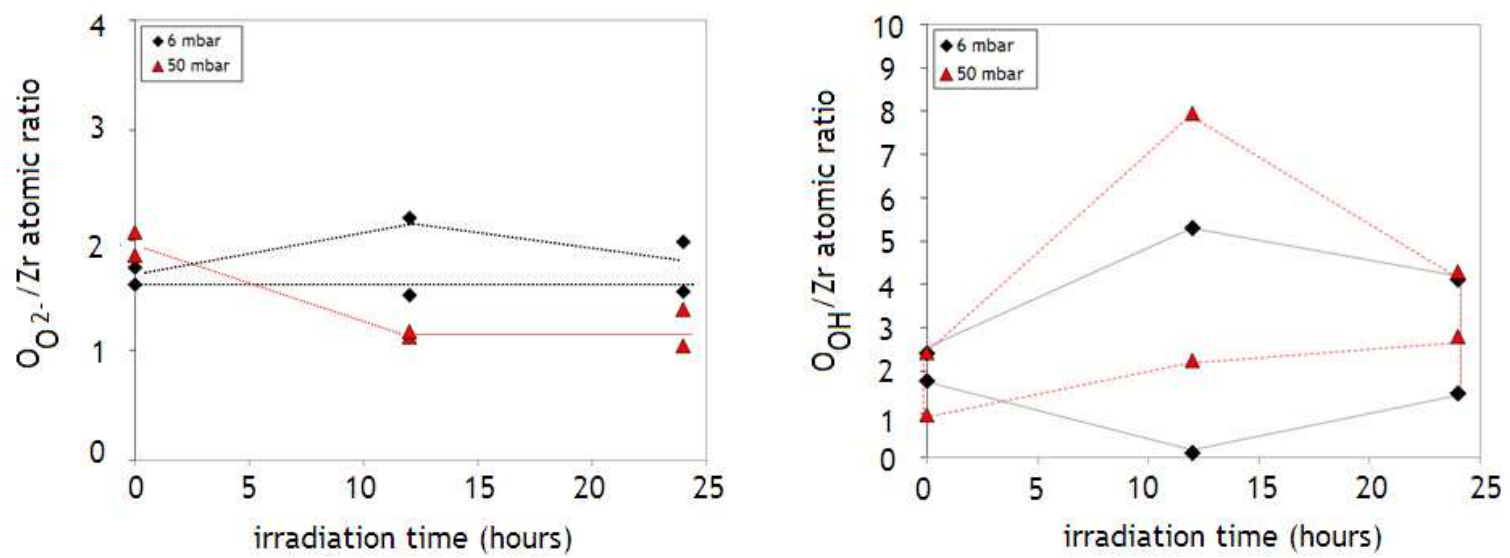

Figure 5: $\mathrm{O}^{2-}$ and $\mathrm{OH}^{-} \mathrm{XPS}$ atomic ratios compared to zirconium at $6 \mathrm{mbar}$ (diamond) and $50 \mathrm{mbar}$ (triangle) as a function of irradiation time. The symbol width represents the error bars.

a) 6 mbar

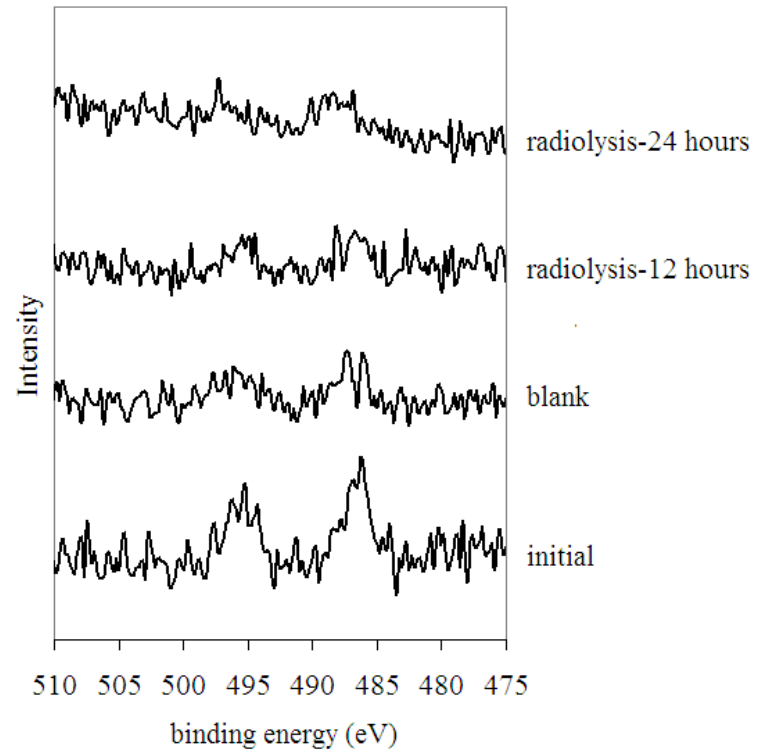

b) $50 \mathrm{mbar}$

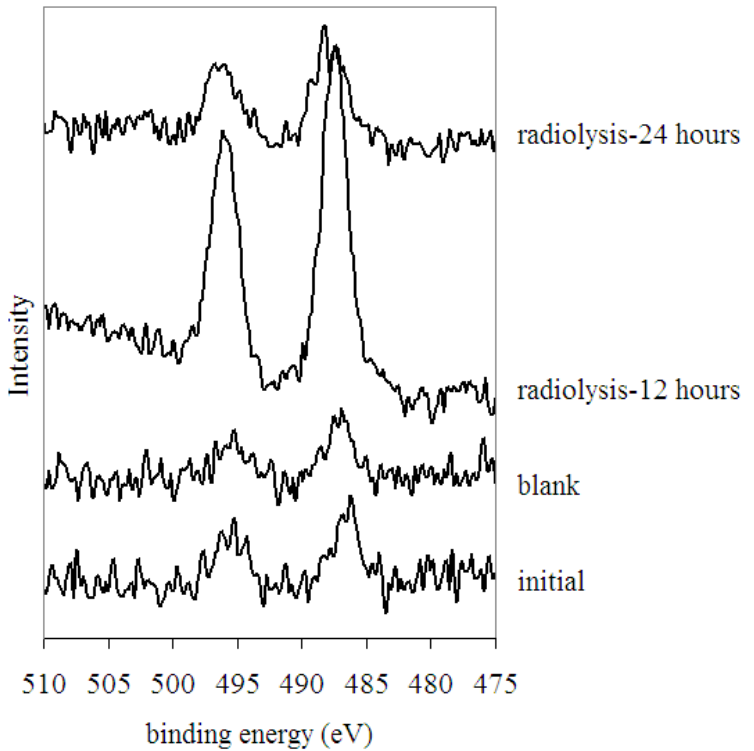

Figure 6: Tin signal after experiments at a) 6 mbar and b) 50 mbar without and with irradiation during 12 and 24 hours 
Nuclear Instruments and Methods in Physics Research Section B: Beam Interactions with Materials and Atoms, 2012, 272, 222-226, doi: 10.1016/j.nimb.2011.01.07O

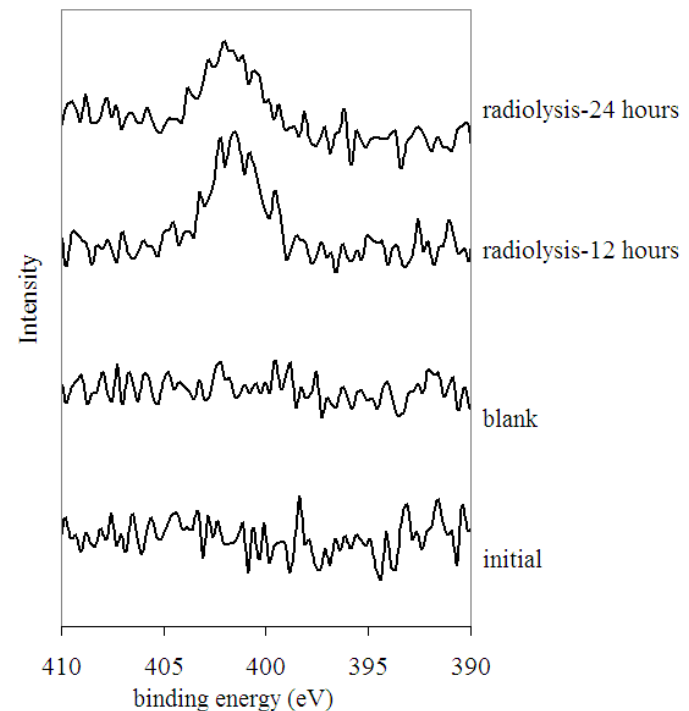

(a) $6 \mathrm{mbar}$

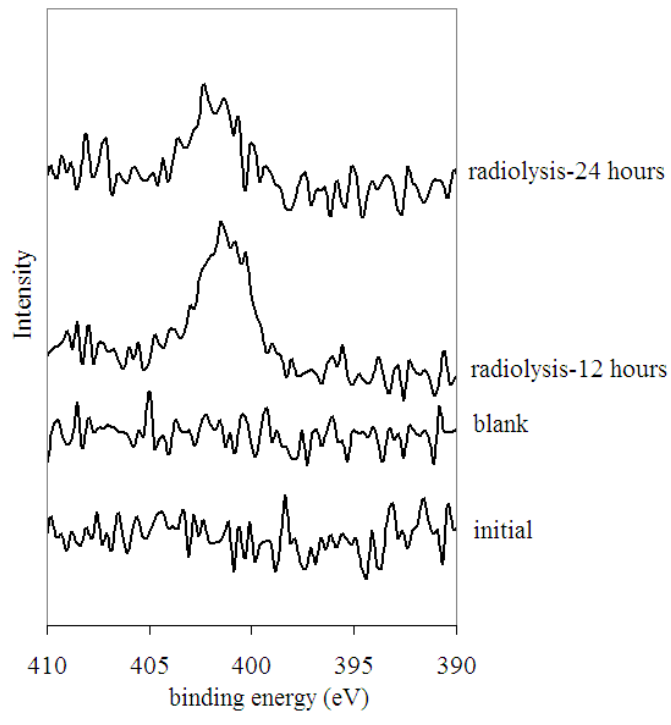

(b) 50 mbar

Figure 7: $N$ signal after experiments at (a) 6 mbar and (b) 50 mbar without and with irradiation during 12 and 24 hours.
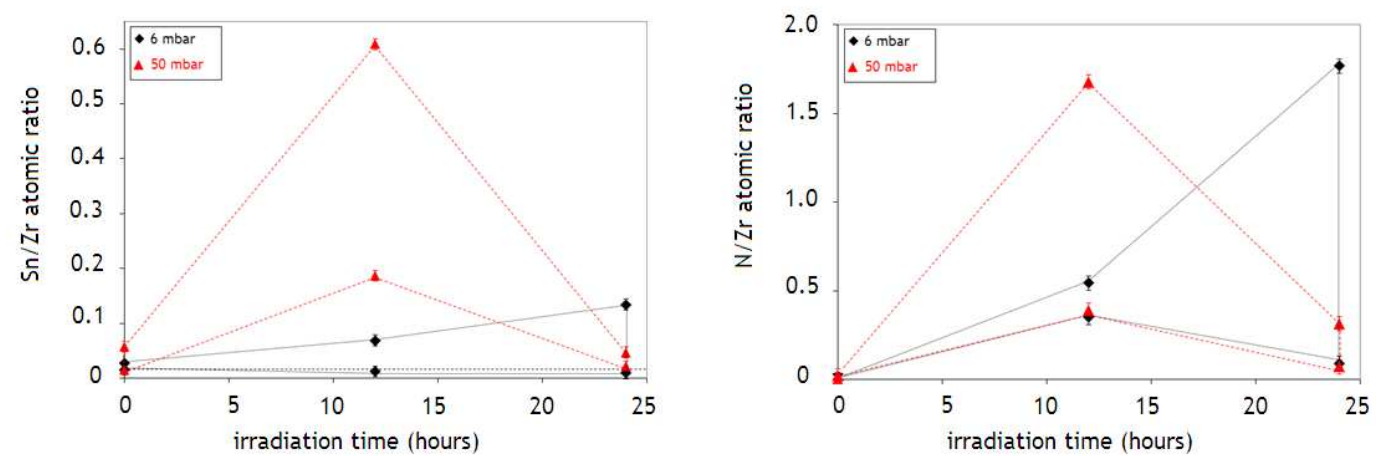

Figure 8: XPS Sn and $N$ atomic ratios compared to zirconium at 6 mbar (diamond) and 50 mbar (triangle). The symbol width represents the error bars.

\section{Tables}

Table 1: $\mathrm{OOH} / \mathrm{Sn}$ and N/Sn atomic ratios from XPS analysis

\begin{tabular}{|l|l|l|l|}
\hline \multicolumn{2}{|c|}{ Blank } & \multicolumn{1}{|c|}{$\mathrm{OH} / \mathrm{Sn}$} & \multicolumn{1}{|c|}{ N/Sn } \\
\hline \multirow{4}{*}{6 mbar } & \multicolumn{1}{|c|}{132} & o \\
\cline { 2 - 4 } & Radiolysis-12 hours & $125-175$ & $8-27$ \\
\cline { 2 - 4 } & Radiolysis-24 hours & $1-72$ & $2-16$ \\
\hline \multirow{5}{*}{50 mbar } & Blank & 128 & 0 \\
\cline { 2 - 4 } & Radiolysis-12 hours & 17 & $1-2$ \\
\cline { 2 - 4 } & Radiolysis-24 hours & $67-75$ & $3-5$ \\
\hline
\end{tabular}

